\title{
Analysis of Spatiotemporal Features of Cassava Evapotranspiration in Benin Using Integrated FAO-56 Method and Terra/MODIS Data
}

\author{
Patrice Koyo ${ }^{1,2}$, Jichao $\mathrm{Hu}^{1} \&$ Martial Amou $^{3}$ \\ ${ }^{1}$ Jiangsu Key Laboratory of Agricultural Meteorology, Nanjing University of Information Science \& Technology, \\ Nanjing, China \\ ${ }^{2}$ College of Atmospheric Sciences, Nanjing University of Information Science and Technology, Nanjing, Jiangsu, \\ China \\ ${ }^{3}$ Institute of Environment and Sustainable Development in Agriculture, Chinese Academy of Agricultural \\ Sciences, Beijing, China \\ Correspondence: Jichao Hu, Jiangsu Key Laboratory of Agricultural Meteorology, Nanjing University of \\ Information Science \& Technology, Nanjing, 210044, China. Tel: 86-138-1392-3708. E-mail: \\ jchu2005@126.com
}

$\begin{array}{lcc}\text { Received: May 8, 2020 } & \text { Accepted: June 19,2020 Online Published: July 15, } 2020 \\ \text { doi:10.5539/jas.v12n8p106 } & \text { URL: https://doi.org/10.5539/jas.v12n8p106 }\end{array}$

The research is financed by Jiangsu Key Laboratory of Agricultural Meteorology Foundation and National Natural Science Foundation of China.

\begin{abstract}
This study analyzed the temporal and spatial features of cassava evapotranspiration from 1985 to 2015 in Benin using linear regression, Mann-Kendall trend test, Sen's slope estimator, and interpolation. The study used basic meteorological data from the Met office of Benin and the Terra/MODIS vegetation index. The estimated crop coefficients $(\mathrm{Kc})$ from FAO and NDVI have shown a strong and positive linear relationship with a correlation coefficient of $r=0.968$, while NDVI-Kc presented values slightly lower than FAO-Kc. The rates of crop evapotranspiration (ETc) varied from 1.23 to $7.63 \mathrm{~mm} /$ day and $2.92 \mathrm{~mm} /$ day on average. At the local level, there were significant upward trends in the seasonal ETc for stations located in the bimodal rainfall pattern area (Cotonou, Bohicon, and Save) and non-significant for stations in the unimodal rainfall pattern area (Kandi, Parakou, and Natitingou). At the country level, both methods revealed a non-significant positive trend in cassava evapotranspiration in the study area while showing a strong and positive linear relationship in variations throughout the growing season, $r=0.956$. Cassava's growth in Benin may encounter in the future the risk of water deficit.
\end{abstract}

Keywords: evapotranspiration, cassava, spatial, temporal, Benin

\section{Introduction}

Cassava is one of the major food crops in Benin both for its direct consumption and for processing into gari, tapioca, cassava chips, and lafun, as well as for its economic implications as an important trade product. Growth of cassava extends throughout the country except for the agro-ecological zone of the Far North covering Karimama, Malanville and North Kandi Municipalities where the climate characteristics are not suitable for the crop growth even though cassava is a drought-resistant crop. Since the warning of the Intergovernmental Panel on Climate Change about global increase in evapotranspiration as result of a warming climate (IPCC, 2014), and the recent study of (Ndehedehe et al., 2018) on evapotranspiration dynamics over Sub-Sahara Africa which indicated an increasing trend of evapotranspiration in Benin, much more attention are drawn on how this may affect major crops of the country including cassava. Evapotranspiration (ET) is the combination of the loss of water from soils by evaporation and from crops by transpiration. ET plays a crucial role in the heat and mass fluxes of global and regional atmospheric systems. Understanding the mechanism of evapotranspiration is vital in hydrological and agricultural studies at the global, regional, and local scales (Xu et al., 2014). Crop water requirement (CWR) should be equal to the ET under ideal crop growth conditions. The FAO-56 method has been the most widely and practical approach used for estimating crop water requirement and the operational 
monitoring of the soil-plant water balance. In this approach, crop evapotranspiration is estimated by the combination of reference evapotranspiration (ETo) and crop coefficients (Allen et al., 1998). ETo in some cases is referred to as potential evapotranspiration (PET), which is defined as the maximum rate at which water, if available, can be removed from soil and plant surfaces under no-stress condition. As a key process in land surface studies, the reference evapotranspiration (ETo) mainly depends on two parameters, water availability and incoming solar radiation, and then reflects the interactions between surface water processes and climate (Sobrino et al., 2007). Two different approaches were developed by FAO-56 to determine crop evapotranspiration: single and dual crop coefficients. In the single crop coefficient approach, both plant transpiration and soil evaporation are combined into a single crop coefficient $(\mathrm{Kc})$, while the dual crop coefficient approach uses two coefficients to separate the respective contribution of plant transpiration $(\mathrm{Kcb})$ and soil evaporation $(\mathrm{Ke})$, each by individual values (Allen et al., 1998).

It is well established that canopy cover intercepts sunlight then making the ratio of crop coefficient to canopy declined with a higher amount of canopy cover and structure (Trout \& Gartung, 2006). Due to that dependent character of Kc on the dynamics of the canopies (cover fraction, LAI, greenness), Remote sensing data can thus be used to estimate some key-variables related to vegetation phenology (Bastiaanssen et al., 2000), which offer opportunities for monitoring spatial and temporal variability of Kc (Farg et al., 2012). The remote sensed vegetation indices such as Normalized Difference Vegetation Index (NDVI) and the Soil Adjusted Vegetation Index (SAVI) have been successfully used and positively tested to predict crop coefficients at the field and regional scales (Duchemin et al., 1998; Huete, 1988).

In recent years, the increasing interest to understand global warming and its possible impacts on crop production has led many researchers to examine the variability and change of potential evapotranspiration and even to predict its future fluctuations based on the future climate state. Determination of the crop evapotranspiration (ETc), which is based on daily Kc, is a key requirement for the sound of agricultural management and irrigation (Bezerra et al., 2010). This study, therefore, aimed to obtain Kc for each growing stage from tabulated FAO-56 Kc values and numerical Kc calculation, and through a careful analysis of the temporal NDVI values from the Terra/MODIS vegetation index product (MOD13Q1) by determining cassava evapotranspiration over past three (1985-2015) decades and across different regions. This study is an attempt to contribute to the existing literature on the variability of cassava crop evapotranspiration in time and space in Benin.

\section{Materials and Methods}

\subsection{Study Area}

Benin is located on the West African coast, bordering Nigeria to the East, Niger to the North, Togo to the West, Burkina Faso to the Northwest and the Atlantic Ocean to the South, with a total surface area of $112,622 \mathrm{sq} . \mathrm{km}$. It lies between $6^{\circ} 10^{\prime}$ and $12^{\circ} 25^{\prime}$ North latitude and between $0^{\circ} 45^{\prime}$ and $3^{\circ} 55^{\prime}$ East longitude. The climate in Benin is influenced by the Inter-Tropical Conversion Zone (ITCZ), creating winds from the Ocean as well as from the Sahara region that are dustier and warmer (Mcsweeney et al., 2010). The resulting annual West African Monsoon from the two opposing wind directions causes a wet season in the North from May to November and two wet seasons from March to July and from September to November in the Southern regions (GOB, 2018; Mcsweeney et al., 2010). This highly influences the derived eight agro-ecological zones available to the agrarian economy of Benin. The current study covers the whole country by focusing on the six synoptic station areas of the country.

\subsection{Data Sets}

Observed weather data such as precipitation, maximum and minimum temperatures were obtained from Benin Meteorological Admiration on a daily basis for the six (06) synoptic stations over the period 1985-2015. Figure 1 shows the stations and their geographic distribution in the study area.

The NASA's Terra Moderate Resolution Imaging Spectroradiometer (MODIS) satellite data was accessed from The Land Processes Distributes Active Archive Center (LP DAAC) https://pdaac.usgs.gov/. The Vegetation Indices (MOD13Q1) Version 6 data are generated every 16 days at a 250-meter spatial resolution as a Level 3 product and provides two primary vegetation layers (Didan et al., 2015). 


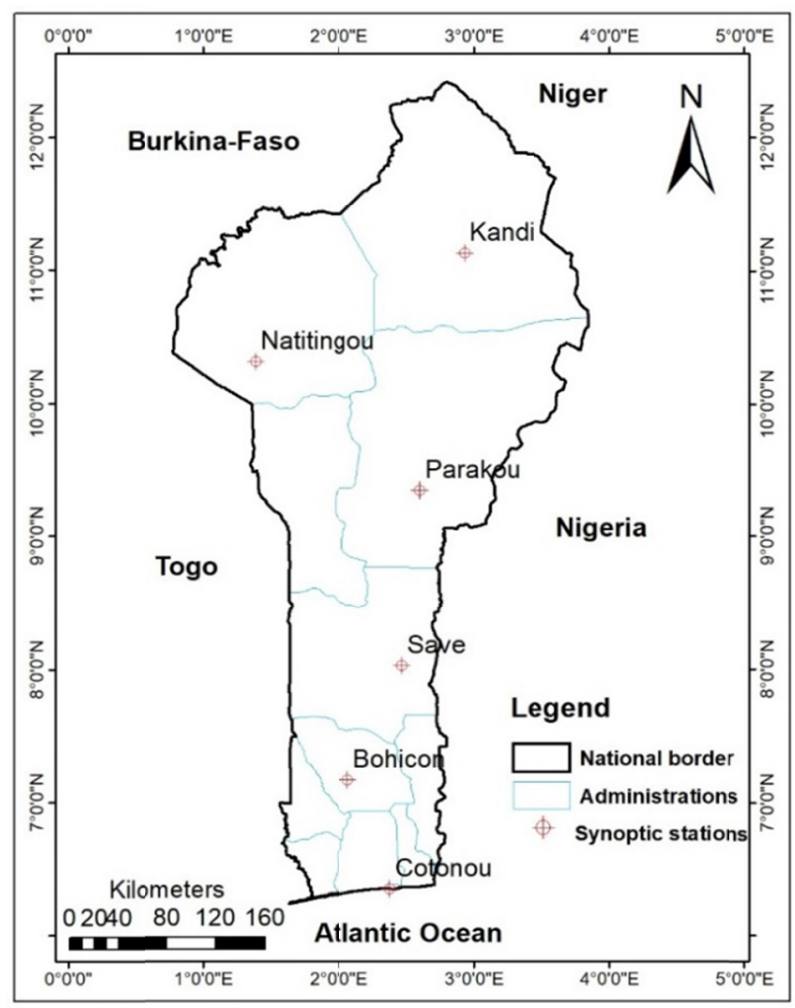

Figure 1. The map of Benin showing the synoptic stations of Benin (selected case study areas)

\subsection{Methods}

\subsubsection{ETc and Kc Calculations}

Figure 2 summarizes the research methodology. The FAO method known as the single coefficient approach is widely recommended for calculation of crop evapotranspiration with limited data on soil conditions (Allen et al., 1998; El-shirbeny et al., 2014). The single coefficient approach combines into a single coefficient (noted Kc) the difference between the evapotranspiration of the cropped and reference grass (Allen et al., 1998). The daily value of ETc was calculated using the following equation:

$$
\mathrm{ETc}=\mathrm{Kc} \times \mathrm{ETo}
$$

Where, ETc is the crop evapotranspiration [mm/day], $\mathrm{Kc}$ is the crop coefficient [dimensionless] and ETo is the reference crop evapotranspiration [mm/day]. 


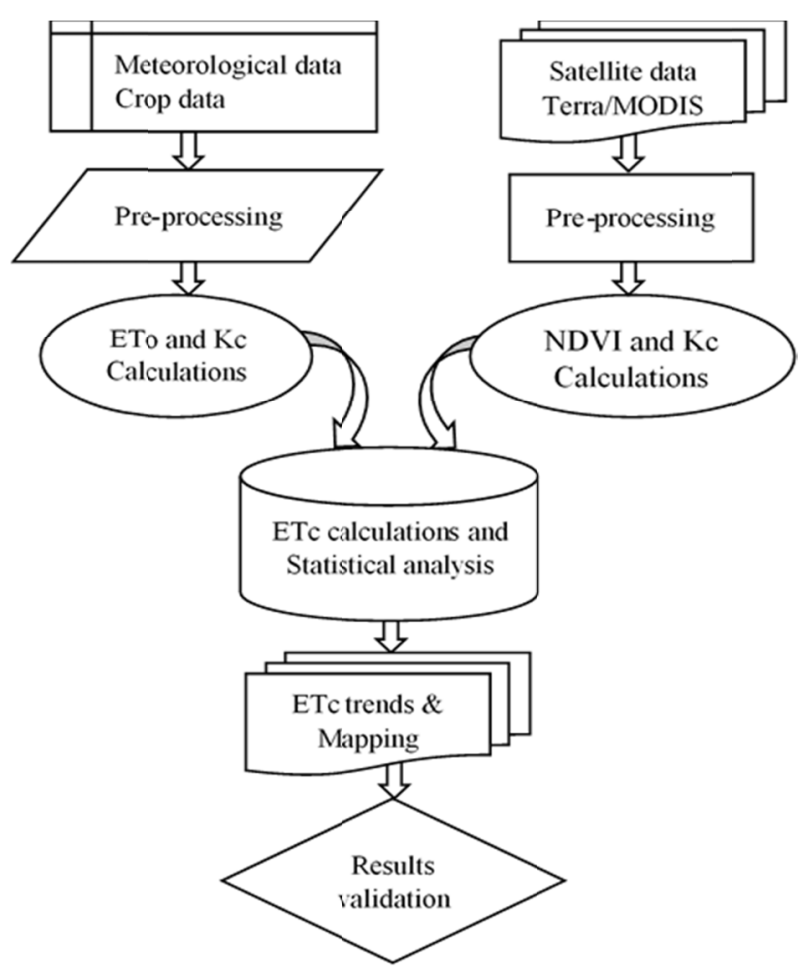

Figure 2. The research flowchart

As the ground cover, canopy properties, and aerodynamic resistance of the crop are different from grass, the crop evapotranspiration differs distinctly from the reference evapotranspiration (Allen et al., 1998). It is a function of minimum and maximum temperatures, solar radiation, wind speed, and humidity. Due to data limitation, the calculation of reference evapotranspiration is done using the Hargreaves Equation (2) below (Hargreaves \& Samani, 1982; Hargreaves et al., 2003).

$$
\mathrm{ET}_{\mathrm{o}}=0.0023\left(\mathrm{~T}_{\text {mean }}+17.8\right) \mathrm{Kr}\left(\mathrm{T}_{\max }-\mathrm{T}_{\text {min }}\right)^{0.5} \times \mathrm{R}_{\mathrm{a}}
$$

Where, Ra is extraterrestrial radiation $\left[\mathrm{MJ} / \mathrm{m}^{2} /\right.$ day $], \mathrm{T}_{\min }$ and $\mathrm{T}_{\max }$ are minimum and maximum air temperatures $\left[{ }^{\circ} \mathrm{C}\right], \mathrm{K}_{\mathrm{r}}$ is the empirical coefficient, which has a suggested value of 0.17 for interior lowlands (Allen, 1996), and $\mathrm{T}_{\text {mean }}$ is the mean of the daily maximum $\left(\mathrm{T}_{\max }\right)$ and minimum $\left(\mathrm{T}_{\min }\right)$ temperatures.

To better estimate the daily Kc for the crop over the entire growing season, Equation (3) was used (Allen et al., 1998). The equation considers that during the initial and mid-season stages $\mathrm{Kc}$ is constant and equal to the $\mathrm{Kc}$ value of the growth stage under consideration. During the crop development and late-season stage, $\mathrm{Kc}$ varies linearly between the $\mathrm{Kc}$ at the end of the previous stage $\left(\mathrm{K}_{\mathrm{c} \text { prev }}\right)$ and the $\mathrm{Kc}$ at the beginning of the next stage $\left(\mathrm{Kc}_{\text {next }}\right)$, which is $\mathrm{Kc}$ at the end in the case of the late-season stage:

$$
\mathrm{K}_{\mathrm{ci}}=\mathrm{K}_{\mathrm{c} \mathrm{prev}}+\left[\frac{\mathrm{i}-\sum\left(\mathrm{L}_{\text {prev }}\right)}{\mathrm{L}_{\text {stage }}}\right]\left(\mathrm{K}_{\mathrm{c} \text { next }}-\mathrm{K}_{\mathrm{c} \mathrm{prev}}\right)
$$

Where, $i$ is day number within the growing season [L ... length of the growing season], $\mathrm{K}_{\mathrm{ci}}$ is crop coefficient on day $i$, Lstage is the length of the stage under consideration [days] and $\sum$ (Lprev) is the sum of the lengths of all previous stages [days].

To import Terra/MODIS data into ArcGIS for further analysis, the data went through a resampling using the nearest neighbor (NN) method, and the file format then changed from HDF-EOS into a georeferenced tagged image file format (GeoTIFF). The spatially extracted NDVI across the study area has then served as input for estimating the Kc using the equation below (El-shirbeny et al., 2014):

$$
\mathrm{Kc}=\frac{0.8}{\mathrm{NDVI}_{\max }-\mathrm{NDVI}_{\min }}\left(\mathrm{NDVI}-\mathrm{NDVI}_{\min }\right)
$$

Where, $\mathrm{NDVI}_{\max }$ and $\mathrm{NDVI}_{\min }$ are maximum and minimum values of NDVI respectively. The value 0.8 is the maximum Kc value for cassava reported in FAO paper (Allen et al., 1998). The Kc was computed based on the season and the corresponded NDVI values. 


\subsubsection{Trend Analysis and Spatial Distribution}

The total seasonal ETc at each station was plotted in RStudio software and the linear regression fitted with the correlation coefficient. A simple linear regression of the form $y=a x+b$ was used to compute the linear trend. $x$ and $\mathrm{y}$ are the independent and dependent variable respectively, $\mathrm{a}$ and $\mathrm{b}$ are constants to be determined by minimizing the function:

$$
\mathrm{Q}=\sum_{\mathrm{i}=1}^{\mathrm{n}}\left[\mathrm{y}_{\mathrm{i}}-\left(\mathrm{ax}_{\mathrm{i}}+\mathrm{b}\right)\right]=0
$$

An assessment of the trend over time was done by computing Mann-Kendall statistical test with the associated two-sided p-values (Hipel \& McLeod, 2005; Mann, 1945). Due to the limitation of Mann Kendall to provide information about the magnitude of the significant trends (Fuwape \& Ogunjo, 2018), Sen's slope was used alongside. The Mann-Kendall test statistics $\mathrm{S}$ is based on the pair-wise comparison of each data points with all preceding data points (Khambhammettu, 2005).

$$
\mathrm{S}=\sum_{\mathrm{k}=1}^{\mathrm{n}-1} \sum_{\mathrm{j}=\mathrm{k}+1}^{\mathrm{n}} \operatorname{sgn}\left(\mathrm{x}_{\mathrm{j}}-\mathrm{x}_{\mathrm{k}}\right)
$$

Where, $\mathrm{n}$ is the length of the time series $\mathrm{x}_{1}, \ldots \mathrm{x}_{\mathrm{n}}, \operatorname{sgn}(\cdot)$ is a sign function while $\mathrm{x}_{\mathrm{j}}$ and $\mathrm{x}_{\mathrm{k}}$ are values in years and we have:

$$
\operatorname{Sgn}\left(x_{j}-x_{k}\right)=\left\{\begin{array}{c}
1, \text { if } x_{j}-x_{k}>0 \\
0, \text { if } x_{j}-x_{k}=0 \\
-1, \text { if } x_{j}-x_{k}<0
\end{array}\right\}
$$

A very high positive (low negative) value of $S$ is an indicator of an increasing (decreasing) trend. The variance of $\mathrm{S}$ was computed by the formula:

$$
\sigma^{2}(S)=\frac{1}{18}\left[n(n-1)(2 n+5)-\sum_{p=1}^{q} \operatorname{tp}(t p-1)(2 t p+5)\right]
$$

Where, $q$ and $t_{p}$ are respectively the number of tied groups and the number of data values in the $p^{\text {th }}$ group (Hipel and McLeod, 2005; Mann, 1945)The $Z$ test statistics is as follows (Khambhammettu, 2005):

$$
Z=\left\{\begin{array}{c}
\frac{\mathrm{S}-1}{\sqrt{\sigma^{2}(\mathrm{~S})},} \text { if } \mathrm{S}>0 \\
0, \text { if } \mathrm{S}=0 \\
\frac{\mathrm{S}+1}{\sqrt{\sigma^{2}(\mathrm{~S})}}, \text { if } \mathrm{S}<0
\end{array}\right\}
$$

The spatial distribution was assessed by interpolation in ArcMap 10.3.1 (ArcGIS software). A study has assessed three interpolation methods to interpolate regional ETc distribution by spline, ordinary kriging (OK), Ordinary Co-kriging (OC) and inverse distance weighting (IDW), using station data (Ashraf et al., 1997; Dalezios et al., 2002), the general finding was that the IDW method gave the lowest mean error among the three common interpolation methods (Chuanyan et al., 2005). Given this reason, the inverse distance weighting (IDW) technique was adopted in the course of this study as it is revealed to give the lowest mean error compared to others.

\section{Results}

\subsection{Crop Coefficients}

The crop coefficients were estimated from FAO-56 default values and NDVI on daily basis over the length of the cropping cycle. There is a strong linear relationship with a correlation coefficient of $r=0.968$ between both crop coefficients while the Root Mean Squared Error is RMSE $=0.079$. The linear relationship between the Kc was also reflected within the seasonal ETc. The NDVI-Kc though presented values slightly different from those of FAO-Kc, showing very similar variation all through the cropping cycle including the growing stages. Generally, FAO-Kc is markedly higher than NDVI-Kc. However, NDVI-Kc tend to have a higher value at the end of the late-season stage (day 210) when compared with FAO-Kc for the same stage. It is also remarkable that Kc during the first 20 days of growth is not constant as suggested in FAO paper (Allen et al., 1998). Over the length of the growth cycle, even for the periods of the first 20 days and between day 60 and day 150, during which FAO-Kc has constant values, there is a slight variation in the NDVI-Kc. The crossing of the two Kc lines between the days 174 and 177 showed that the two sources Kc have the same values during those days, while the FAO-Kc decreased faster than the NDVI-Kc over the period laying between day 150 and day 210. 
FAO-Kc \& NDVI-Kc time series

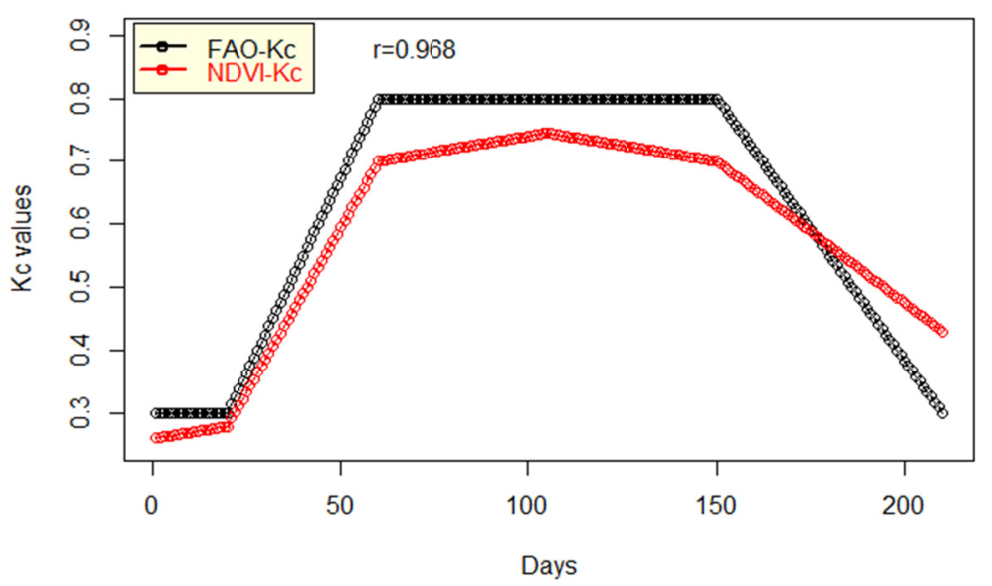

Figure 3. Relationship between FAO-Kc and NDVI-Kc

\subsection{Trends Analysis and Spatial Distribution}

Figure 4 and Table 1 present the summary of the changes in the cassava seasonal ETc over years and the results of the Mann Kendall test Sen's slope respectively. The seasonal ETc for cassava here is the total sum of the daily ETc over the entire length of the growth cycle (from the sowing to full maturity), which is 210 days, the period between March-September in the Southern and May-November in the Northern.

To understand the climatic characteristics in which cassava grows throughout the country, we have made a brief analysis of the main climate elements (temperature and rainfall) at each station under consideration during the growing period of cassava. The highest maximum and minimum temperatures recorded during cassava growth length for the six stations were $30.29^{\circ} \mathrm{C}$ and $25.48{ }^{\circ} \mathrm{C}, 32.46{ }^{\circ} \mathrm{C}$ and $23.88^{\circ} \mathrm{C}, 32.95{ }^{\circ} \mathrm{C}$ and $23.47{ }^{\circ} \mathrm{C}, 34.40{ }^{\circ} \mathrm{C}$ and $23.29{ }^{\circ} \mathrm{C}, 32.65{ }^{\circ} \mathrm{C}$ and $22.27{ }^{\circ} \mathrm{C}, 32.94{ }^{\circ} \mathrm{C}$ and $21.73{ }^{\circ} \mathrm{C}$, for Cotonou, Bohicon, Save, Kandi, Parakou and Natitingou respectively, while on average, the corresponding total rainfall amounts were $1122.05 \mathrm{~mm}, 945.09$ $\mathrm{mm}, 439.59 \mathrm{~mm}, 958.83 \mathrm{~mm}, 1008.2 \mathrm{~mm}, 1094.37 \mathrm{~mm}$. On average, the maximum temperature throughout cassava cropping season in Cotonou, Bohicon, Save, Kandi, Parakou and Natitingou were $29.79{ }^{\circ} \mathrm{C}, 31.56{ }^{\circ} \mathrm{C}$, $31.92{ }^{\circ} \mathrm{C}, 33.29^{\circ} \mathrm{C}, 31.24{ }^{\circ} \mathrm{C}$, and $31.89^{\circ} \mathrm{C}$, respectively, and the corresponding minimum values of $24.78{ }^{\circ} \mathrm{C}$, $23.12{ }^{\circ} \mathrm{C}, 22.50{ }^{\circ} \mathrm{C}, 22.61{ }^{\circ} \mathrm{C}, 21.71{ }^{\circ} \mathrm{C}$ and $21.21^{\circ} \mathrm{C}$. 

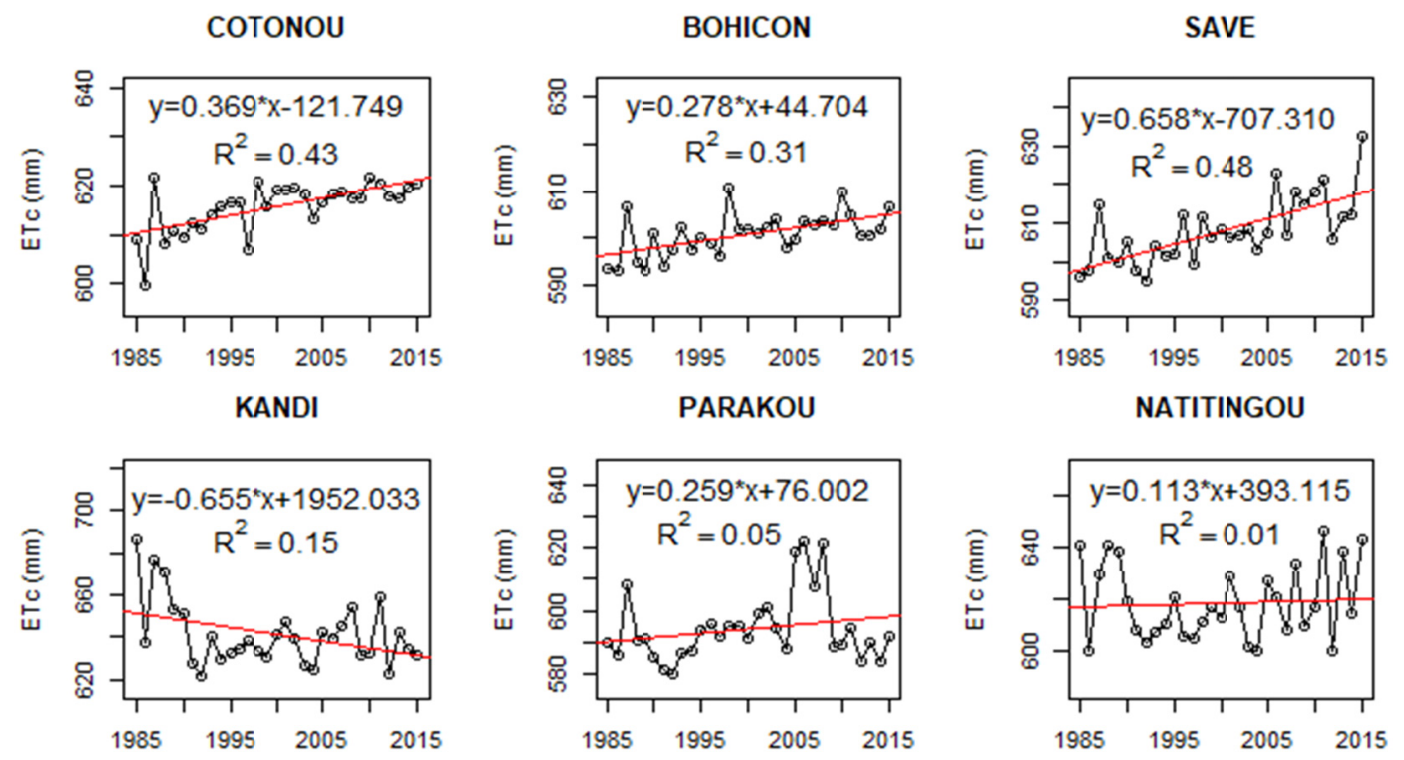

Figure 4. The trends in mean seasonal Cassava ETc at the local level

Table 1. Summary of Mann-Kendall test of the trends in Cassava ETc at the local level

\begin{tabular}{llllll}
\hline Location & $\mathrm{n}$ & Test Z & $\mathrm{p}$-value & Significance & Sen's slope \\
\hline Cotonou & 31 & 3.8752 & $1.07 \mathrm{E}-04$ & $* * *$ & 0.364459 \\
Bohicon & 31 & 3.3653 & 0.000765 & $* * *$ & 0.310414 \\
Save & 31 & 4.1811 & $2.90 \mathrm{E}-05$ & $* * *$ & 0.630739 \\
Kandi & 31 & -1.2237 & 0.221 & n.s & -0.38232 \\
Parakou & 31 & 1.2917 & 0.1965 & n.s & 0.189743 \\
Natitingou & 31 & 0.37392 & $7.09 \mathrm{E}-01$ & n.s & 0.136763 \\
\hline
\end{tabular}

Note. n.s.: not Significant; ***: Significant at $0.01 \%$.

There is a notable trend at all the stations with slight differences in the rates of change. Seasonally, ETc varied from 599.71 to $621.89 \mathrm{~mm}$ in Cotonou, from 592.95 to $610.46 \mathrm{~mm}$ in Bohicon, from 594.99 to $632.30 \mathrm{~mm}$ in Save, from 622.01 to $687.02 \mathrm{~mm}$ in Kandi, from 580.05 to $622.21 \mathrm{~mm}$ in Parakou, and from 599.63 to 646.49 $\mathrm{mm}$ in Natitingou (Figure 4). Cassava seasonal ETc reached its minimum (580.05 mm) in Parakou, whereas Kandi recorded the maximum value, $687.02 \mathrm{~mm}$. At the country level, the seasonal ETc ranged on average between 594.32 and $641.22 \mathrm{~mm}$ (Figure 5). The $p$-values associated with the Mann-Kendall test are statistically significant, suggesting the presence of a statistically significant upward trend in the seasonal ETc for the stations located in the two rainy seasons area (Cotonou, Bohicon, and Save). This could be due to the bimodal rainfall pattern available in those regions There are very significant $(p<0.001)$ positive trends at the rate of 0.36 $\mathrm{mm} /$ year at Cotonou, $0.31 \mathrm{~mm} /$ year at Bohicon, and $0.63 \mathrm{~mm} /$ year in Save. Negative trend was observed in Kandi $(Z=-1.22)$,positive trends in Parakou $(Z=1.29)$ and Natitingou $(Z=0.37)$ for cassava ETc, Mann-Kendall test revealed non-significant trends $(p>0.05)$ for the three stations with respective Sen's slope of $-0.38 \mathrm{~mm} /$ year, $0.19 \mathrm{~mm} /$ year, and $0.14 \mathrm{~mm} /$ year (Table 1). This paradox of the negative trend observed in Kandi is related to the single rainfall season that prevails in that region, and indicates that the area is unsuitable for cassava growth. This was confirmed by the Food and Agriculture Organization of the United Nations' investigation stating that the Northern Kandi is unsuitable for cassava growth (http://www.fao.org/agriculture/ seed/cropcalendar/cropcalendar.do). Moreover, the Southern Kandi where cassava cultivation is possible is steadily reported to be under the threats of climate change (Hounnou \& Dedehouanou, 2018; Sohou, 2017).

The daily cassava evapotranspiration obtained from the product of ETo and Kc (Equation 1) over the period between the sowing day to the day of full maturity represents ETc rate. The rate of cassava evapotranspiration ranged between 1.24 and $6.08 \mathrm{~mm} /$ day, 1.24 and $5.82 \mathrm{~mm} /$ day, 1.16 and $5.09 \mathrm{~mm} /$ day, 1.14 and $7.67 \mathrm{~mm} /$ day, 1.18 and $5.89 \mathrm{~mm} /$ day, and between 1.23 and $6.08 \mathrm{~mm}$ /day in Cotonou, Bohicon, Save, Kandi, Parakou, and Natitingou respectively. The lowest rates registered in the Southern region (Cotonou, Bohicon, and Save) were 
mainly during the short dry season lying between late July and August while the highest rates observed were during the rainy season. (Watanabe et al., 2004) also found similar rates of cassava evapotranspiration in Northeast Thailand. On average, the rates were $2.93 \mathrm{~mm} /$ day in Cotonou, $2.85 \mathrm{~mm} /$ day at Bohicon, $2.90 \mathrm{~mm} /$ day at Save, $3.05 \mathrm{~mm} /$ day in Kandi, $2.83 \mathrm{~mm} /$ day in Parakou, and $2.94 \mathrm{~mm} /$ day in Natitingou, thus ranging from $2.83 \mathrm{~mm} /$ day (in Parakou) to $3.05 \mathrm{~mm} /$ day (in Kandi) with an overall mean value of $2.92 \mathrm{~mm} /$ day for the entire country.

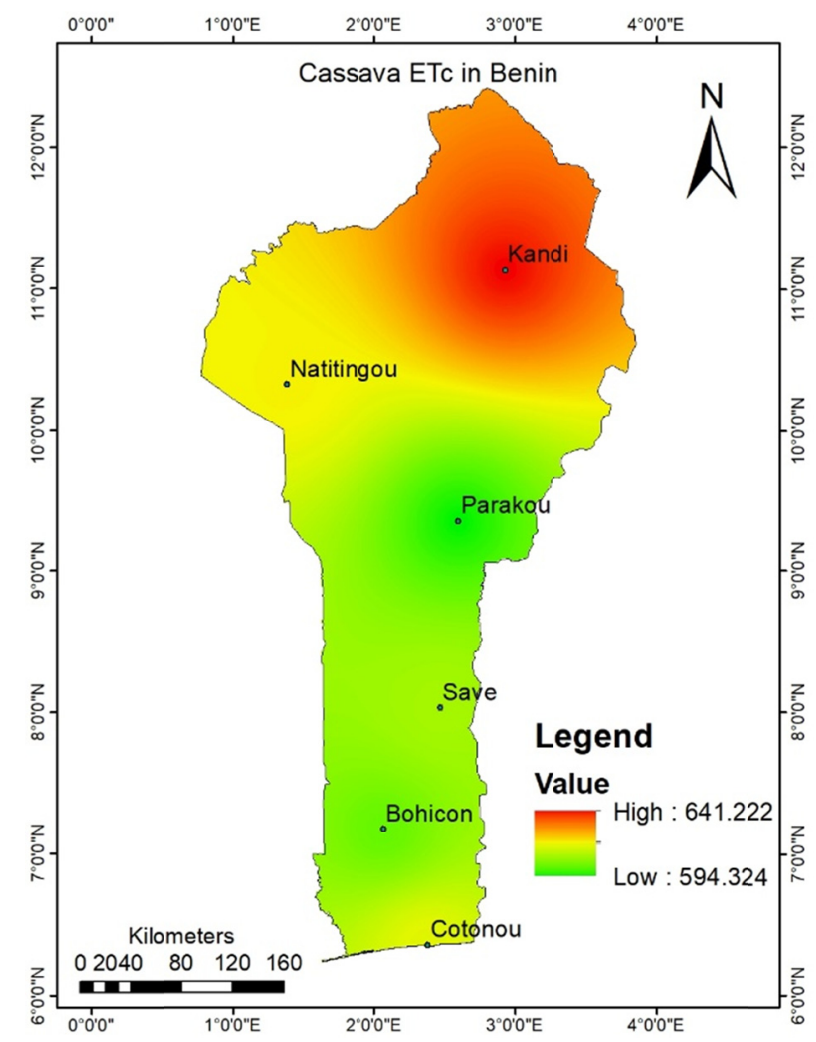

Figure 5. The spatial distribution of mean seasonal ETc of Cassava in Benin

As revealed through the climatic characteristic analysis of the study area during the growing season, the trends analysis (Table 1) and the spatial distribution above (Figure 5), the seasonal ETc for cassava crop is mostly higher in the Northern than it is in the Southern part of the country. The values increased as we move northward to reach the peak at Kandi. That suggested a crop water requirement higher than can be supplied by the rainfall in the area, this confirms the unsuitability of the largest part of this zone for cassava growth along with the full decline of the suitable one (Sohou, 2017). Apart from Cotonou-the rainiest zone in the study area, other zones where high values of evapotranspiration were recorded were in mountainous zones with an altitude ranging from 200 to 500 meters.

The positive trends of evapotranspiration along the years as observed at almost all the stations for the crop under consideration reflects an increase in irrigation water demand. This finding is supported by Djaman et al., (2017) who also found an overall increasing trend of pan evaporation in Togo.

\subsection{Comparison Between ETc at the Country Level}

The $p$-values associated with the Mann-Kendall test are statistically non-significant despite the positive trends showed in both ETc. The two methods revealed the same result (a non-significant positive trend) concerning the trends in cassava evapotranspiration in the study area. Both results for cassava evapotranspiration obtained using FAO-Kc and NDVI-Kc (Figure 6) approaches displayed similar variation during the growing stages. However, the satellite-based estimated ETc has relatively lower values when compared with that of the FAO-Kc based estimated ETc. The first ranged from 561.26 to $586.29 \mathrm{~mm}$ whereas the second from 601.52 to $626.24 \mathrm{~mm}$ showing an underestimation of the first and/or an overestimation of the second. The same observation holds for the daily rates of evapotranspiration over the entire growing period. 


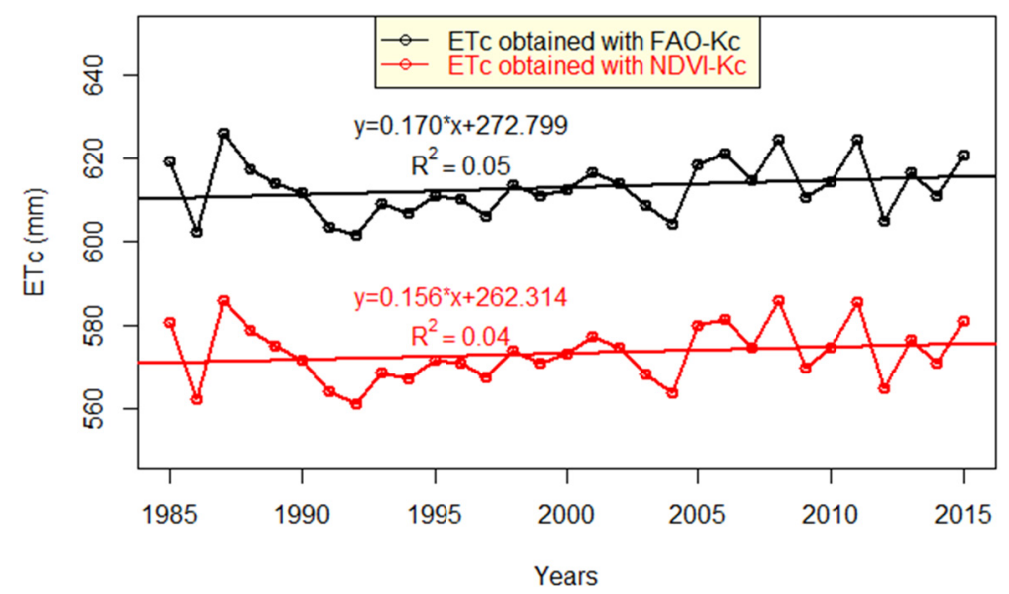

Figure 6. The trends in mean seasonal Cassava ETc at the country level

Table 2. Summary of Mann-Kendall test of the trends in Cassava ETc at the country level

\begin{tabular}{llllll}
\hline ETc & $\mathrm{n}$ & Test Z & p-value & Significance & Sen's Slope \\
\hline FAO-Kc based & 31 & 1.3597 & $1.74 \mathrm{E}-01$ & n.s. & 0.227895 \\
NDVI-kc based & 31 & 1.1558 & 0.2478 & n.s. & 0.202955 \\
\hline
\end{tabular}

Note. n.s.: not Significant.

\section{Conclusion}

This study investigated the temporal and spatial features of cassava evapotranspiration from 1985 to 2015 in Benin using linear regression, Mann-Kendall trend test, Sen's slope estimator, and interpolation by inverse distance weighting (IDW). The study collected data from the Met office of Benin - daily rainfall, minimum and maximum air temperatures - and used the Terra/MODIS vegetation index. The FAO-56 paper has helped with the tabulated crop coefficient $\mathrm{Kc}$ values. The reference crop evapotranspiration was computed at the station level using Hargreaves Samani formula based on the available data for the study. The estimated Kc from FAO and NDVI have shown a strong and positive linear relationship with a correlation coefficient of $r=0.968$. ETc rates varied from 1.23 to $7.63 \mathrm{~mm} /$ day and $2.92 \mathrm{~mm} /$ day on average. At the local level, there were significant upward trends in the seasonal ETc over 1985-2015 for the stations located in the bimodal rainfall pattern area (Cotonou, Bohicon, and Save) and non-significant for the stations in the unimodal rainfall pattern area (Kandi, Parakou, and Natitingou). At the country level, both methods revealed a non-significant positive trend in cassava evapotranspiration in the study area while showing a strong linear relationship between their variations all through the growing season, $r=0.956$. Cassava's growth in Benin may soon encounter the risk of water deficit as result of increasing loss of water from cassava crop due to the warming climate.

There is no experimental data on crop coefficients in Benin at the moment of this study and it is thus impossible to examine the eventual errors, uncertainties, and even the degree of accuracy of the calculated NDVI-Kc (for the considered crop of this study) to validate it for further use. This is a limitation of the study. Further study on soil water is recommended for understanding the ranges of additional irrigation water needed for proper crop growth during the rainy season in the case of water shortage and even for the dry season crop growth. Therefore, the need for decision-makers and stakeholder onto be aware of this alarming decrease rates (speed) of soil water within each agro-ecological zone for both the rainy and dry seasons.

\section{Acknowledgements}

This work was supported by Jiangsu Key Laboratory of Agricultural Meteorology Foundation (JKLAM1805) and National Natural Science Foundation of China (41875140). We are thankful to China Scholarship Council (CSC) for offering the opportunity to study at Nanjing University of Information Science and Technology in China, Benin government, and Benin Meteorological Administration for providing the climatic data.

\section{References}

Allen, R. G. (1996). Assessing integrity of weather data for reference evapotranspiration estimation. Journal of 
Irrigation and Drainage Engineering, 122(2), 97-106. https://doi.org/10.1061/(ASCE)0733-9437(1996) 122:2(97)

Allen, R. G., Pereira, L. S., Raes, D., \& Smith, M. (1998). FAO Agriculture Series (Vol. 13). FAO Irrigation and Drainage Paper No. 56. https://doi.org/10.1016/S0141-1187(05)80058-6

Ashraf, M., Loftis, J. C., \& Hubbard, K. G. (1997). Application of geostatistics to evaluate partial weather station networks. Agricultural and Forest Meteorology, 1923(1973), 255-271. https://doi.org/10.1016/S0168-1923 (96)02358-1

Bastiaanssen, W. G. M., Molden, D. J., \& Makin, I. W. (2000). Remote sensing for irrigated agriculture: Examples from research and possible applications. Agricultural Water Management, 46, 137-155. https://doi.org/10.1016/S0378-3774(00)00080-9

Bezerra, B. G., Barbosa, B., Silva, D. A., Cortez, J. R., Brandão, Z. N., Centro, E., ... Grande, C. (2010). Evapotranspiração Real Obtida Através Da Relação Entre O Coeficiente Dual De Cultura Da Fao-56 E O NDVI. Revista Brasileira de Meteorologia, 25, 404-414. https://doi.org/10.1590/S0102-778620100 00300012

Chuanyan, Z., Zhongren, N., \& Guodong, C. (2005). Methods for modelling of temporal and spatial distribution of air temperature at landscape scale in the southern Qilian mountains, China. Ecological Modelling, 189, 209-220. https://doi.org/10.1016/j.ecolmodel.2005.03.016

Dalezios, N. R., Loukas, A., \& Bampzelis, D. (2002). Spatial variability of reference evapotraspiration in Greece Spatial variability of reference evapotranspiration in Greece. Physics and Chemistry of the Earth, 27(December), 1031-1038. https://doi.org/10.1016/S1474-7065(02)00139-0

Didan, K., Munoz, A. B., \& Huete, A. (2015). MODIS Vegetation Index User's Guide (MOD13 Series, 2015, June).

Djaman, K., Koudahe, K., \& Ganyo, K. K. (2017). Trend Analysis in Annual and Monthly Pan Evaporation and Pan Coefficient in the Context of Climate Change in Togo. Journal of Geoscience and Environment Protection, 05(12), 41-56. https://doi.org/10.4236/gep.2017.512003

Duchemin, B., Frappart, F., Chehbouni, M. M. G., Dedieu, G., Maisongrande, P., \& Mougenot, B. (1998). Water Budget with Phenology derived from Optical Satellite Data, 500.

El-shirbeny, M. A., Ali, A. M., \& Saleh, N. H. (2014). Crop Water Requirements in Egypt Using Remote Sensing Techniques. Journal of Agricultural Chemistry and Enviroment, 3(April), 57-65. https://doi.org/10.4236/ jacen.2014.32B010

Farg, E., Arafat, S. M., Abd El-Wahed, M. S., \& EL-Ginly, A. M. (2012). Estimation of Evapotranspiration ET c and Crop Coefficient K c of Wheat, in south Nile Delta of Egypt Using integrated FAO-56 approach and remote sensing data. The Egyptian Journal of Remote Sensing and Space Sciences, 15(1), 83-89. https://doi.org/10.1016/j.ejrs.2012.02.001

Fuwape, I. A., \& Ogunjo, S. T. (2018). Modeling of raining season onset and cessation of tropical rainfall for climate change adaptation in Agriculture. Physics. Ao-Ph, 1-19. Retrieved from http://arxiv.org/abs/ 1811.09677

GOB (Government of Benin). (2018). Climate Change Profile, Benin. Government of Benin, Ministry of Foreign Affairs.

Hargreaves, G. H., \& Samani, Z. A. (1982). Estimating potential evapotranspiration. Journal of Irrigation and Drainage Engineering, 225-230.

Hargreaves, G. H., Asce, F., \& Allen, R. G. (2003). History and Evaluation of Hargreaves Evapotranspiration Equation. Journal of Irrigation and Drainage Engineering, 129(February), 53-63. https://doi.org/10.1061/ (ASCE)0733-9437(2003)129:1(53)

Hipel, K. W., \& McLeod, A. (2005). No TitleTime Series Modelling of Water Resources and Environmental Systems. Retrieved from http://www.stats.uwo.ca/faculty/aim/1994Book

Hounnou, F. E., \& Dedehouanou, H. (2018). Variability of Temperature, Precipitation and Potential Evapotranspiration Time Series Analysis in Republic Of Benin. International Journal of Agriculture and Environment Research, 04(December), 991-1019.

Huete, A. R. (1988). A Soil-Adjusted Vegetation Index (SAVI). Remote Sensing of Enviroment, 309, $295-309$. 
https://doi.org/10.1016/0034-4257(88)90106-X

IPCC. (2014). Climate Change 2014: Synthesis Report. Contribution of Working Groups I, II and III to the Fifth Assessment Report of the Intergovernmental Panel on Climate Change. Managing the Risks of Extreme Events and Disasters to Advance Climate Change Adaptation: Special Report of the Intergovernmental Panel on Climate Change (Vol. 9781107025). https://doi.org/10.1017/CBO9781139177245.003

Khambhammettu, P. (2005). Appendix D-Mann-Kendall Analysis for the Fort Ord Site. Annual Groundwater Monitoring Report.

Mann, H. B. (1945). Nonparametric tests against trend. Econometrica, 13, 245-259. https://doi.org/10.2307/ 1907187

Mcsweeney, C., \& New, M., Lizcano, G., \& Lu, X. (2010). The UNDP Climate Change Country Profiles Improving the accessibility of Observed and Projected Climate Information for Studies of Climate Change in Developing Countries. American Meteorological Society, February, 157-166. https://doi.org/10.1175/ 2009BAMS2826.1

Ndehedehe, C. E., Okwuashi, O., Ferreira, V. G., \& Agutu, N. O. (2018). Exploring evapotranspiration dynamics over Sub-Sahara Africa (2000-2014). Environmental Monitoring and Assessment, 190(7). https://doi.org/ 10.1007/s10661-018-6780-6

Sobrino, J. A., Gómez, M., Jiménez-Muñoz, J. C., \& Olioso, A. (2007). Application of a simple algorithm to estimate daily evapotranspiration from NOAA-AVHRR images for the Iberian Peninsula. Remote Sensing of Enviroment, 110, 139-148. https://doi.org/10.1016/j.rse.2007.02.017

Sohou, E. B. (2017). Benin agriculture in front of climate change: Challenges and implications: Kandi case. Forestry Research and Engineering: International Journal, 1(2), 67-68. https://doi.org/10.15406/freij.2017. 01.00011

Trout, T., \& Gartung, J. (2006). Use of crop canopy size to estimate crop coefficient for vegetable crops. Examining the Confluence of Environmental and Water Concerns-Proceedings of the World Environmental and Water Resources Congress 2006 (970). https://doi.org/10.1061/40856(200)297

Watanabe, K., Yamamoto, T., Yamada, T., Sakuratani, T., Nawata, E., Noichana, C., ... Higuchi, H. (2004). Changes in seasonal evapotranspiration, soil water content, and crop coefficients in sugarcane, cassava, and maize fields in Northeast Thailand. Agricultural Water Management, 67(2), 133-143. https://oi.org/ 10.1016/j.agwat.2004.02.004

Xu, Y. P., Pan, S., Fu, G., Tian, Y., \& Zhang, X. (2014). Journal of Geophysical Research: Atmospheres. Journal of Geophysical Research: Atmospheres, 118, 2174-21992. https://doi.org/10.1002/2013JD021245

\section{Copyrights}

Copyright for this article is retained by the author(s), with first publication rights granted to the journal.

This is an open-access article distributed under the terms and conditions of the Creative Commons Attribution license (http://creativecommons.org/licenses/by/4.0/). 